\section{The immobility reaction in leopard frogs (Rana pipiens) as a function of noise-induced fear}

\author{
RICHARD F. NASH, GORDON G. GALLUP, JR, and MICHAEL K. MCCLURE \\ Tulane University, New Orleans, La. 70118
}

Thirty-four frogs served as Ss, with half receiving a loud noise just prior to being immobilized, while the remainder served as a control group. Those exposed to preinduction noise remained immobile significantly longer than did the controls. The results were discussed as providing additional support for the idea that the immobility response represents an innate fear reaction.

The immobility response is well documented in a wide variety of animal species (see review by Ratner, 1967). The reaction is usually induced by manual restraint and is characterized by physical immobility and reduced responsiveness. Theoretical explanations of the phenomenon have been numerous and diverse, including cerebral inhibition, sleep, hypnosis, spatial disorientation, death feigning, and paralysis due to fear (Ratner, 1967). In recent years the paralysis-due-to-fear hypothesis has received the most support but mainly from studies invoking it postdictively. Salzen (1963) found that the fear response (immobility) in chickens was in part a function of the difference between the nature of the test situation and the extent of the chick's past experiences. Studies by Ratner \& Thompson (1960) and Gilman, Marcuse, \& Moore (1950) obtained results that lend support to the idea that unfamiliarity with the test situation is a critical variable influencing the occurrence of the immobility response and offered interpretations based on the fear hypothesis.

More recently, Gallup, Creekmore, \& Hill (1970) found that duration of the immobility response was enhanced in domestic chickens by the administration of preinduction electric shock. Based on the hypothesis that increasing the level of fear above that produced by manual restraint should prolong the duration of the response, subsequent studies in our laboratory have shown that the visual orientation of the $E, 1$ the intensity of preinduction shock, and the administration of a loud preinduction noise, ${ }^{2}$ all lead to enhanced immobility reactions in domestic chickens.

The present study was undertaken in an attempt to obtain some cross-species data on the experimental manipulation of fear as it relates to the immobility reaction in frogs. It was hypothesized that a loud preinduction noise should prolong the duration of immobility by increasing the level of fear or arousal prior to manual restraint.

\section{SUBJECTS}

The Ss were 34 leopard frogs (Rana pipiens) with an average body length of from 7.5 to $9.0 \mathrm{~cm}$, obtained from the West Jersey Biological Supply Farm. The frogs were housed in two aquaria, with about $1.9 \mathrm{~cm}$ of water in the bottom of each, and were maintained in the laboratory by force feeding them fresh horse meat.

\section{APPARATUS}

The equipment consisted of a Pyrex dish, $25.4 \times 15.9 \times 4.5 \mathrm{~cm}$, lined with moist paper, which served as the induction trough, and a small portable signal horn (Hamilton Power Pack), which generated a low-frequency sound of about $120 \mathrm{~dB}$, as measured by a General Radio sound-level meter (Model 1551-C). A stopwatch was used to record the duration of immobility reactions.

\section{PROCEDURE}

After being handled briefly three times on the preceding day, the Ss were tested. The $E$ selected a $S$ at random from one aquarium, carried it to the testing room in a plastic container, and tested it under one of two conditions. The experimental condition consisted of holding the frog while the horn was positioned about $8 \mathrm{~cm}$ from the S's head and sounded for about $1 \mathrm{sec}$. The $S$ was then immediately inverted and manually restrained on its back in the induction trough for $30 \mathrm{sec}$, after which time the $E$ removed his hands and started the stopwatch. Self-paced termination of the immobility response was used, and as soon as the $\mathrm{S}$ righted itself, the duration of immobility was recorded. A ceiling of $900 \mathrm{sec}$, which pilot work showed to be reasonable, was placed on the duration of the response in the interest of economy of time. The control condition was similar to the experimental condition, except that the horn was not sounded. The Ss were tested in a fixed order alternating between experimental and control conditions, resulting in $17 \mathrm{Ss}$ per group.

\section{RESULTS AND DISCUSSION}

Frogs exposed to the loud noise prior to manual restraint remained immobile almost eight times longer than did the controls. Figure 1 depicts the mean duration of immobility exhibited by $S s$ in the experimental (noise) and control groups. Due to greater variability in the experimental group $(S D=202.24)$ as compared to the control ( $S D=22.35$ ), a square-root transformation was performed on the data. A random-groups analysis of variance run on the transformed scores yielded a significant difference between the two conditions $(F=5.84, \quad \mathrm{df}=1 / 32$, $\mathrm{p}<.025)$, indicating that preinduction exposure to a loud noise produced a reliable effect. As a further check, a nonparametric test was run on the data to discount the possibility that the difference between the two conditions was due solely to a few rather extreme scores in the experimental condition. A Mann-Whitney $U$ test yielded a significant difference between the two treatments $(U=77.5$, $p<.01$ ), thereby confirming that the two distributions were indeed different.

The results replicate those obtained in our laboratory using domestic chickens in showing that a loud preinduction noise extends the duration of the immobility reaction. These cross-species data provide further evidence in support of the fear hypothesis. While Gallup et al (1970) used preinduction shock to increase arousal or fear, the use of a loud noise should negate any possible confounding due to physiological factors and provide for a more unambiguous test of the fear hypothesis.

\section{REFERENCES}

GALLUP, G. G., JR., CREEKMORE, H. S., \& HILL, W. E., III. Shock-enhanced immobility reactions in chickens: Support for the fear hypothesis. Psychological Record, 1970, in press.

GILMAN, T. T., MARCUSE, F. L., \& MOORE, A. M. Animal hypnosis: A study in the

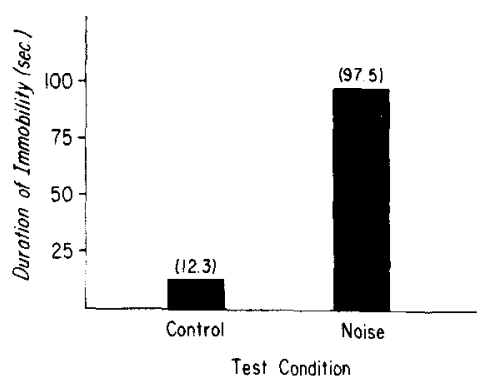

Fig. 1. Mean duration of immobility as a function of the test conditions (horn vs no horn). 
Induction of tonic immobility in animals. Journal of Comparative \& Physiological Psychology, 1950, 43, 99-111.

RATNER. S. C. Comparative aspects of hypnosis. In J. I. Gordon (Ed.), Handbook of clinical and experimental hypnosis. New York: Macmillan, 1967. Pp. 550-587.

RATNER, S. C., \& THOMPSON, R. W. Immobility reactions (fear) of domestic fowl as a function of age and prior experiences. Animal Behaviour, 1960, 8, 186-191.

SALZEN, E. A. Imprinting and the immobility reactions of comestic towl. Animal Behaviour, $1963,11,66-71$.

\section{NOTES}

1. Gallup, G. G., Jr., Cummings, W. H., \& Nash, R. F. The experimenter as an independent variable in studies of animal hypnosis. Submitted for publication.

2. Gallup, G. G., Jr., Nash, R. I., Potter, R. J., \& Donegan, N. H. The effect of varying conditions of fear on immobility reactions in domestic chickens (Gallus gallus). Submitted for publication.

\section{Repeated acquisition as a behavioral baseline*}

\section{DONALD M. THOMPSON \\ Georgetown University Schools of Medicine and Dentistry, Washington, D.C. 20007}

The Boren (1963) technique for studying variables affecting acquisition with an individual-S design was modified and used with pigeons. The sensitivity and reversibility of the steady-state baseline were demonstrated by temporarily removing the different stimuli correlated with the different members of the chain. This "tandem" probe produced a substantial increase in the number of learning errors.

Boren (1963) reported a technique for studying variables affecting acquisition using an individual-S design. Briefly, the learning situation was as follows: Each $\mathbf{S}$ (rhesus monkey) worked for food reinforcement in a chamber containing 12 levers arranged in four groups of three. "For each session the monkey's task was to learn a new four-response chain by pressing the correct lever in each group. A stable pattern of learning resulted, and the number of errors reached a steady state from session to session [Boren \& Devine, 1968 , p. 651]." This steady state of repeated acquisition was then used as a baseline to study the effects of timeout and "instructional" stimuli.

In the present research the Boren technique was modified and used with pigeons. It was hoped that the modification would keep the baseline procedures functionally equivalent but permit more flexibility in varying the difficulty of the learning task, e.g., increasing chain length. More specifically, the four groups of three response keys in the chain were differentiated by color rather than by position. The steady state of repeated acquisition of such chains was then used as a baseline to study the effect of a "tandem" probe.

\section{SUBJECTS}

The Ss were two 5-year-old male

*This research was supported in part by Public Health Service Grants FR 5360 and FR 5306. experimentally naive White Carneaux pigeons. They were maintained at $80 \%$ of free-feeding weight. Water was always available in the home cages.

\section{APPARATUS}

The apparatus was a standard three-key pigeon chamber (LVE Model 1519B) and connecting automatic control equipment. The scheduling of events was accomplished by means of timers, steppers, and associated relay circuitry; the recording by counters and a 20-pen event recorder. White noise was continuously present in the chamber to mask extraneous sounds.

\section{PROCEDURE}

Throughout the following procedures the primary reinforcer was food (5-sec access to mixed grain). Presentation of the food magazine was accompanied by the offset of the key lights, the offset of the houselight (which was on only during magazine training and shaping), and the onset of the magazine light. Each session terminated after 60 food presentations. A "blackout" (all lights off) of variable duration preceded and followed each session. With few exceptions, there were six daily sessions a week.

Preliminary training included magazine training, shaping of key pecking, and reinforcing pecks on each of the three keys, which were transilluminated with white lights. Then the birds were trained to make a chain of responses. At first, food presentation was contingent upon a chain of two responses. The three keys were transilluminated with red lights, and a peck on any key changed the lights to white. Then, when the bird pecked any of the white keys, it received food, after which the red key lights reappeared, etc. In the same way the chain was gradually extended to include the two other colors. The FR 1 (CRF) food contingency was in effect for the entire chain; i.e., the bird pecked the keys four times, once in the presence of the yellow, green, red, and white lights, with the final peck followed by access to grain. This preliminary training required four sessions.

Baseline
The fifth session was the first baseline session. Now responses on only specified keys from each set of colors led to food presentation, e.g., keys yellow: left correct; keys green: right correct: keys red: center correct; keys white: right correct; food. The same sequence (LRCR) was repeated throughout the session. When the pigeon pecked an incorrect key (a key not included in the above sequence), the error was followed by a 15 -sec time-out. During the time-out, the key lights were off and food was unavailable. An error did not reset the sequence, i.e., the key lights after the time-out were the same color as before the time-out. For convenience, each completion of the sequence was considered a "trial," even though there was no "intertrial interval" as conventionally defined. The errors made during a trial were recorded separately for each color, and their reduction during a 60-trial session was taken as an index of the rate of learning.

The sequence of correct key positions was changed from session to session. Following Boren, the sequences were carefully selected to be equivalent in several ways, and there were restrictions on their ordering across sessions. First, a correct color position in one session was not repeated in the following session. Second, simple orders, such as the left key in each group of colors, were avoided. In fact, in the present research, adjacent positions in each sequence were always different, although each position occurred at least once. Third, within a set of six sequences, each key position appeared equally often (twice) in each color. An example of a typical set of six sequences is as follows: LRCR, CLRL, LRLC, RCRL, CLCR, RCLC; the order of the associated colors was always the same: yellow, green, red, white (food).

\section{Probe}

When the rate of learning had stabilized from session to session (40-60 days), a temporary change in procedure ("probe") was introduced. Different colored key 